\section{Occurrence of Vibrio parahaemolyticus, Vibrio cholerae and Vibrio vulnificus in the clam Ruditapes philippinarum (Adams \& Reeve, 1850) from Emilia Romagna and Sardinia, Italy}

\author{
Pier Luca Passalacqua, \\ Emanuele Zavatta, Giorgia Bignami, \\ Andrea Serraino, Patrizia Serratore \\ Department of Veterinary Medical \\ Science, Alma Mater Studiorum- \\ University of Bologna, Ozzano Emilia \\ (BO), Italy
}

\section{Abstract}

Marine vibrios, Vibrio parahaemolyticus, $V$. vulnificus and $V$. cholerae are responsible of the majority of food-borne human infections by consumption of bivalve shellfish. The aim of the present study was to ascertain the occurrence of these bacteria, and their potential pathogenicity, in the Manila clam $R$. philippinarum from Emilia Romagna (ER) and Sardinia (SR) regions, Italy. Isolation was performed on CHROMagar ${ }^{\mathrm{TM}}$ vibrio with subculture on (thiosulfate-citrate-bile salts-sucrose) Agar and m-modified-cellobiose-polymyxin bcolistin (-CPC) Agar. Suspected strains were purified, biochemically characterized and genotyped by simplex polymerase chain reaction (PCR) for the specie-specific and pathogenic gene markers: $V$. parahaemolyticus (toxRP, tdh and trh); V. vulnificus (vvhA, hsp, $v c g \mathrm{C}, v c g \mathrm{E}$, CPS operon allele 1, CPS operon allele 2, 16s-rRNA operon allele A, 16s-rRNA operon allele B; V. cholerae (toxRC, hlya, tcpI, tcpA, $\operatorname{ctxA}, \operatorname{ctxB}$, stn/sto). Moreover a multiplex PCR was applied to the SR bivalve shellfish, for the simultaneous detection of the three targets directly on homogenate samples, targeting the species-specific gene for $V$. cholerae (tox $R \mathrm{C}$ ), $V$. parahaemolyticus (toxRP) and $V$. vulnificus $(v v h A)$. As a result of phenotyping and genotyping of isolates, bivalve shellfish from ER resulted positive for $V$. parahaemolyticus (27.8\%) and $V$. vulnificus (10.1\%), but negative for $V$. cholerae. Shellfish from SR resulted positive for $V$. parahaemolyticus (30.3\%), V. vulnificus $(6.1 \%)$ and $V$. cholerae (3\%). No significant differences emerged between the two areas $(\mathrm{P}>0.05)$.

\section{Introduction}

Global total production of fish, crustaceans, molluscs and other aquatic animals has continued to increase in the last decades, as a result of a stable situation of total captures and a strong growth of aquaculture, particularly of bivalve shellfish, hereafter indicated simply shellfish, that reached a worldwide production of 14.8 million tons (FA0, 2014). The Manila clam Ruditapes philippinarum (Adams and Reeve, 1850) is one of the most cultivated species in the world, and Italy is the second producer after China (Turolla, 2008). The national production is concentrated in the North-west Adriatic sea, from Friuli-Venezia Giulia region to Emilia Romagna region, were $R$. philippinarum is cultured. In Sardinia region the production is actually marginal, and mainly by catch, but shows a promising trend for expansion.

As sedentary suspension feeding organisms, shellfish gain nourishment by pumping large volumes of seawater from the environment through their gills, and thus they may accumulate harmful bacteria and viruses resulting in a substantial health risk for the consumers, particularly if they are eaten raw or lightly cooked, as is often the case (Serratore et al., 2014). Focusing on bacterial contaminants, pathogenic vibrios are undoubtedly the most relevant ones from an epidemiological point of view. Members of the genus Vibrio are gram-negative straight or curved roads, ubiquitous in the marine environments. To date, one hundred and thirty species of vibrios have been described and thirteen have been classified as human pathogens (Thandavarayan et al., 2014), but with different epidemiological relevance. $V$. parahaemolyticus, $V$. vulnificus and $V$. cholera are considered a serious and growing public health hazard, whereas infections by the remaining vibrio species are less common and usually less severe, although deaths have been reported (European Commission, 2001).

$V$. cholerae is considered a foodborne pathogen that affects humans and causes cholera, a disease characterized by profuse watery diarrhea and vomiting, which can lead to severe dehydration, hypovolemic shock and, with no appropriate treatment, death. This disease is still a serious problem in some countries of Asia, African regions and Haiti and remains endemic in much of the developing world. In 1994, cholera outbreaks occurred also in Italy and Albania (Pazzani et al., 2006). Actually, more than 200 somatic (cell wall) 0antigen serogroups of $V$. cholerae are recognized, among which only serogroups 01 and 0139 are considered etiologic agents of epidemic and pandemic cholera, but occasional outbreaks of cholera-like disease are also reported (Fykse et al., 2007). The pathogenici-
Correspondence: Patrizia Serratore, Department of Veterinary Medical Science, Special Operative Unit of Aquaculture and Hygiene of Fishery Products, v.le A. Vespucci 2, 47042 Cesenatico (FC), Italy.

Tel: +39.0547 .338948 - Fax: +39.0547 .338941 .

E-mail: patrizia.serratore@unibo.it

Key words: V. parahaemolyticus; V. cholerae V. vulnificus; $R$. philippinarum; Italy.

Contributions: PLP and EZ were involved in the isolation and phenotypical characterization of the bacterial targets. GB was involved in the genotyping of the isolates of interest. AS was involved in the revision of the paper. PS was involved in the analysis of literature, planning of the work, supervision of the laboratory procedures, and writing of the paper.

Conflict of interest: the authors declare no potential conflict of interest.

Funding: this work was funded in part by the Sardinia Region (L.R. 7/8/2007, n. 7, Promozione della ricerca scientifica e dell'innovazione tecnologica in Sardegna), and in part by Euroittica s.r.l. (Rep.89/2013 Prot. n. 2300 del 11/09/2013-TIT. III/19). The views expressed are those of the authors and not of the funding entities.

Received for publication: 21 December 2015 .

Revision received: 22 January 2016.

Accepted for publication: 22 January 2016 .

This work is licensed under a Creative Commons Attribution-NonCommercial 4.0 International License (CC BY-NC 4.0).

(OCopyright P.L. Passalacqua et al., 2016 Licensee PAGEPress, Italy

Italian Journal of Food Safety 2016; 5:5709

doi:10.4081/ijfs.2016.5709

ty of $V$. cholerae 01 and 0139 depends upon the production of virulence factors, such as the toxin co-regulated pilus TCP and the cholera toxin CTX. Other factors associated with enteropathogenicity include: an El Tor-like hemolysin (hlyA), hemagglutinins, neuraminidase, outer membrane protein (ompU), Shiga-like toxin (Stx) and a zonula occludens toxin (Zot) (Rivera et al., 2001). The heat-stable enterotoxin named stn/sto often determines the pathogenicity of environmental non-01 and non-0139 strains (Guglielmetti et al., 1994).

V. parahaemolyticus occurs naturally in the marine environments and may be abundant in shellfish, being recognized as a common cause of acute gastroenteritis worldwide (Ward and Bej, 2006). In Japan, V. parahaemolyticus accounts for approximately $20-30 \%$ of cases of bacterial foodborne infection, being the common cause of seafood-borne illness in many Asian countries, and has been recognized as 
the most frequent cause of Vibrio-associated gastroenteritis in the US (Ceccarelli et al, 2013).

V. parahaemolyticus gastroenteritis is related to the production of two hemolysin: a thermostable direct hemolysin (TDH) and/or a thermostable-related hemolysin (TRH) (Zhang and Austin, 2005). Infections caused by $V$. parahaemolyticus have been associated with diverse serovars, among which 01:K38, 03:K29, 04:K8, 03:K6, 02:K3, 04:K8, with a localized geographical distribution. Serovar 03:K6, showing specific gene markers ( $t d h$, toxRS/New and orf8), may have a pandemic diffusion, (Velasquez-Roman et al., 2014). In Europe, $V$. parahaemolyticus infections have been rarely reported, but the 03:K6 serovar has been isolated from clinical specimens in France, Russia, Spain and Italy (Ottaviani et al., 2008).

V. vulnificus is considered an opportunistic human pathogen that is responsible for $95 \%$ of seafood-related deaths in the US (Williams et al., 2013). Actually, three biogroups are recognized and differentiated by biochemical characteristics: biogroup 1, which is pathogenic to humans, biogroup 2, which is pathogenic to eels, and biogroup 3, which is pathogenic to humans but has only been reported in Israel (Sanjuán et al., 2011). Biogroup 1 infects humans through the ingestion of contaminated seafood or skin lesions, and in healthy individuals may cause gastroenteritis or wound infection, whereas in immunocompromised hosts the infection often leads to primary or secondary septicemia, with a fatality rate exceeding 50 and 25\%, respectively (Han et al., 2011).

For a long time, the identification of Vibrio spp. during epidemiological inquiries was mainly based on phenotypic markers for strains isolated at $37^{\circ} \mathrm{C}$, but this approach is not reliable enough to identify strains collected from environmental samples, mainly because of the adaptation and subsequent phenotypic changes to varying environmental conditions (Tall et al., 2012). Moreover cultural methods utilized alone are incapable to distinguish pathogenic strains from non-pathogenic strains, thus molecular methods were developed to improve the detection and identifica-

Table 1. Biochemical characteristics of Vibrio parabaemolyticus strains isolated in the present study.

\begin{tabular}{|c|c|c|c|c|c|c|c|}
\hline Strain & TCBS & $\begin{array}{c}\text { KIA } \\
\text { (lactose/sucrose// }{ }_{2} \mathrm{~S} / \mathrm{gas} \text { ) }\end{array}$ & Indole & Citrate & ONPG & Gelatinase & $\begin{array}{cc}0 / 129 & \text { Growth } \\
(150-10 \mu g) & \text { at } 42^{\circ} \mathrm{C}\end{array}$ \\
\hline
\end{tabular}

Emilia Romagna

\begin{tabular}{|c|c|c|c|c|c|c|c|c|c|}
\hline VP464/11 & - & KA-/- & $-1+/+$ & + & + & . & + & SS & + \\
\hline VP480/5 & - & $\mathrm{KA}+/-$ & $-/+/+$ & + & + & - & + & SR & + \\
\hline VP501/13 & - & KA-/- & $-/+/+$ & + & + & - & + & SR & + \\
\hline VP510/4 & - & KA-/- & $-/+/-$ & + & + & - & - & SR & + \\
\hline VP628/8 & - & $\mathrm{KA}+/-$ & $-/+/+$ & + & + & - & + & SR & + \\
\hline VP644/11 & - & KA-/- & $-/+/+$ & + & - & - & + & SS & - \\
\hline VP731-11 & - & KA-/- & $-/+/+$ & + & + & - & + & SS & + \\
\hline VP734-5 & - & KA-/- & $-/+/+$ & + & + & - & + & SS & + \\
\hline VP734-12 & - & KA-/- & $-/+/+$ & + & + & - & - & SS & + \\
\hline VP739-9 & - & KA-/- & $-/+/-$ & + & + & - & + & SS & + \\
\hline VP741-12 & - & KA-/- & $-1+/+$ & + & + & + & + & SR & + \\
\hline VP768-12 & - & KA-/- & $-/+/+$ & + & + & - & + & SS & + \\
\hline VP776-1 & - & KA-/- & $-/+/-$ & + & + & - & + & SS & + \\
\hline VP794-4 & - & KA-/- & $-/+/-$ & + & + & - & + & SR & + \\
\hline VP814-3 & - & KA-/- & $-/+/+$ & + & - & - & + & SR & + \\
\hline VP889-4 & - & KA-/- & $-/+/-$ & + & - & - & + & SR & + \\
\hline VP890-3 & - & KA-/- & $-/+/-$ & + & - & - & + & SR & + \\
\hline VP1022-2 & - & $\mathrm{KA}-/++$ & $-/+/+$ & + & + & - & + & SR & + \\
\hline VP1023-1 & - & KA-/- & $-/+/+$ & + & + & - & + & SR & + \\
\hline VP1031-2 & - & KA-/- & $-/+/+$ & + & + & - & + & SR & + \\
\hline VP1048-1 & - & KA-/- & $-/+/+$ & + & + & - & + & SS & + \\
\hline VP1048-6 & + & KA-/- & $-/+/+$ & + & + & - & + & SS & + \\
\hline VP1086-3 & - & KA-/- & $-/+/+$ & + & + & - & + & SS & + \\
\hline VP1087-6 & - & KA--/- & $-/+/-$ & + & + & - & + & SS & + \\
\hline \multicolumn{10}{|l|}{ Sardinia } \\
\hline VP761-10 & - & KA-/- & $-1+/-$ & + & + & - & + & SS & + \\
\hline VP770-1 & - & KA-/- & $-1+/-$ & + & + & - & + & SS & + \\
\hline VP771-1 & - & KA-/- & $-1+/-$ & + & + & + & + & SS & + \\
\hline VP780-2 & - & KA-/- & $-/+/-$ & + & + & - & + & SS & + \\
\hline VP781-1 & + & KA-/- & $-1+/-$ & + & + & - & + & SR & + \\
\hline VP784-1 & - & KA-/- & $-1+1+$ & + & + & - & + & SR & + \\
\hline VP788-3 & - & KA-/- & $-1+/-$ & + & + & - & + & SS & + \\
\hline VP804-8 & - & $\mathrm{KA}-/+$ & $-/+/+$ & + & - & + & + & SR & + \\
\hline VP806-11 & - & $\mathrm{KA}-/+$ & $-1+1-$ & + & - & - & + & SR & + \\
\hline VP857-1 & - & KA-/- & $-1+/+$ & + & + & - & + & SR & + \\
\hline
\end{tabular}

TCBS, thiosulfate-citrate-bile salts-sucrose; KIA, Kligler Iron Agar; ONPG, ortho-nitrophenyl- -galactoside; VP, Vibrio parahaemolyticus; KA, Kligler Agar; S, sensitive; R, resistant. 
tion of culturable strains, mainly based on polymerase chain reaction (PCR) assays.

Vibrios seem to be highly variable in habitat preference (Schmidt et al., 2014); therefore prevalence studies are of paramount importance to define the risk of Vibrio-associated infectious diseases in a specific geographical area. The present study aims to give a contribute of knowledge on the prevalence and potential pathogenicity of $V$. parahaemolyticus, $V$. cholerae, $V$. vulnificus associated to the Manila clam $R$. philippinarum from two Italian regions, Emilia Romagna facing the Adriatic Sea, and Sardinia facing the Tyrrhenian Sea.

\section{Materials and Methods}

This study was performed by different yearlong sampling campaigns, from 2011 to 2014. On the whole 112 batches of $R$. philippinarum were analyzed, 79 from Emilia Romagna (ER) and 33 from Sardinia (SR). Samples from ER were collected at landing and sent to the laboratory the same day, whereas those from SR were sent the day after landing. All samples were transported in isothermal boxes, stored at $6-8^{\circ} \mathrm{C}$ to avoid Vibrio spp. entering viable but non-culturable (VBNC) state, and processed within $24 \mathrm{~h}$.
The abundance of Vibrio spp. was checked on thiosulfate-citrate-bile salts-sucrose (TCBS) agar (Oxoid, Basingstoke, UK) $\mathrm{NaCl}$ $3 \%$ by the spread plate method, and incubation at $20^{\circ} \mathrm{C}$ for $3-5$ days (Serratore et al., 1999). A significant number of colonies were tested to confirm the typical traits of the genus: Gram negative straight or curved rods, oxidase positive, able to reduce nitrate, dextrose fermenting, and sensitive to the vibriostatic $0 / 129$ $(150 \mu \mathrm{g})$. The results were expressed as colony forming units (CFU) $\mathrm{g}^{-1}$. The isolation of $V$. parahaemolyticus, $V$. cholerae, $V$. vulnificus was performed on CHROMagar ${ }^{\mathrm{TM}}$ Vibrio (CAV), following the triple plating methods described by Williams et al. (2013). Suspected colonies of $\mathrm{V}$. vulnificus and $V$. cholerae (turquoise colour) and suspected colonies of $V$. parahaemolyticus (mauve colour), were transferred onto TCBS agar $\mathrm{NaCl} 3 \%$ and modified cellobiose-polymyxin B-colistin (m-CPC) agar, prepared according to the formulation of the Bacteriological Analytical Manual (Kaysner and DePaola, 2004). Presumptive V. parahaemolyticus strains (green on TCBS Agar, no growth on m-CPC Agar), presumptive $V$. cholerae strains (yellow on TCBS Agar, purple on mCPC Agar), and presumptive $V$. vulnificus strains (green or yellow on TCBS Agar, yellow on m-CPC Agar), were purified on trypticase soy agar (TSA; Oxoid) $\mathrm{NaCl} 3 \%$, tested for the genus-typical traits and then phenotypically characterized following the laboratory protocol, a slight modification of the scheme proposed by Alsina and Blanch as revised by Noguerola and Blanch (2008).

The strains tentatively confirmed to belong to the species of interest were genotyped by simplex PCR, following an internal protocol, for the specie-specific and pathogenic gene markers: toxRP, tdh and trh for $V$. parahaemolyticus; toxRC, hlya, tcpI, tcpA, ctxA, ctxB, stn/sto for $V$. cholerae; vvhA, hsp, vcgC, $v c g$ E CPS operon allele 1, CPS operon allele 2, 16s-rRNA type $A$ gene, 16s-rRNA type $B$ gene for $V$. vulnificus (Serratore et al., 2009). Briefly, a small amount of the purified strain was picked from the plate and transferred in $100 \mu \mathrm{L}$ of sterile $\mathrm{H}_{2} \mathrm{O}$. The DNA was extracted by the boiling method at $100^{\circ} \mathrm{C}$ for $15 \mathrm{~min}$, stored $2-3$ min at $-20^{\circ} \mathrm{C}$ and then centrifuged at $5.000 \mathrm{x} \mathrm{g}$ at $4^{\circ} \mathrm{C}$ for $15 \mathrm{~min}$, recovering the supernatant. Bacterial lysates were stored at $20^{\circ} \mathrm{C}$ until use. For the PCR reactions $1 \mu \mathrm{L}$ of each lysate was suspended with $2.5 \mu \mathrm{L} 10 \mathrm{X}$ PCR Rxn Buffer (Invitrogen, Carlsbad, CA, USA), $1 \mu \mathrm{L} \mathrm{MgSO}_{4}$ (Invitrogen), $0.5 \mu \mathrm{L}$ dNTPs $100 \mathrm{Mm}$ (Invitrogen), $1 \mu \mathrm{L}$ of each primer, $0.2 \mu \mathrm{L}$ of Taq-DNA Polymerase (Invitrogen), and sterile $\mathrm{H}_{2} \mathrm{O}$ to the mark of $25 \mu \mathrm{L}$. PCR reactions were electrophoresed at $100 \mathrm{~V}$ for $30 \mathrm{~min}$ on $1.5 \%$ agarose gel utilizing tris-acetate-eth-

Table 2. Biochemical characteristics of Vibrio vulnificus and Vibrio cholerae strains isolated in the present study.

\begin{tabular}{|c|c|c|c|c|c|c|c|c|c|c|}
\hline Strain & $\begin{array}{c}\text { Cellobiose } \\
\text { (m-CPC) }\end{array}$ & TCBS & KIA & $\mathrm{A} / \mathrm{L} / \mathrm{O}$ & Indole & Citrate & ONPG & Gelatinase & $\begin{array}{c}0 / 129 \\
(150-10 \mathrm{~g})\end{array}$ & $\begin{array}{l}\text { Growth } \\
\text { at } 42^{\circ} \mathrm{C}\end{array}$ \\
\hline \multicolumn{11}{|c|}{ Emilia Romagna } \\
\hline W628-7 & + & - & $\mathrm{KA} /-/-$ & $-1+/+$ & + & - & + & + & SS & + \\
\hline W731-16 & + & + & $\mathrm{KA} /-/-$ & $-/+/-$ & + & - & + & + & SS & + \\
\hline W731-17 & + & + & KA-/- & $-/+/+$ & + & - & + & - & SS & + \\
\hline W731-18 & + & + & KA-/- & $-/+/+$ & + & + & + & + & SS & + \\
\hline W734-4 & + & - & KA/-/- & $-/+/-$ & + & - & + & - & SS & + \\
\hline W734-6 & + & - & KA/-/- & $-/+/-$ & + & - & + & + & SS & + \\
\hline W734-8 & + & + & KA-/- & $-/+/+$ & + & - & + & - & SS & + \\
\hline W734-13 & + & - & KA/-/- & $-/+/-$ & + & + & + & + & SS & + \\
\hline W734-15 & + & - & KA-/- & $-/+/-$ & + & - & + & + & SS & + \\
\hline W734-16 & + & - & KA/-/- & $-/+/-$ & + & - & + & + & SS & + \\
\hline W734-17 & + & - & KA/-/- & $-/+/-$ & + & - & + & - & SS & + \\
\hline W734-18 & + & - & $\mathrm{KA} /-/-$ & $-1+/-$ & + & - & + & - & SS & + \\
\hline W759-14 & + & - & KA-/- & $-/+/-$ & + & + & + & + & SS & + \\
\hline W776-6 & + & - & $\mathrm{KA} /-/-$ & $-1+1-$ & + & + & + & + & SS & + \\
\hline W776-8 & + & - & KA--/- & $-/+/+$ & + & - & + & + & SS & + \\
\hline W776-10 & + & + & KA/-/- & $-/+/+$ & + & - & + & + & SS & + \\
\hline W786-10 & $\mathrm{NG}$ & - & $\mathrm{KA}+/+$ & $-|-|+$ & + & - & + & + & $\mathrm{SS}$ & + \\
\hline W1023-4 & + & - & KA/-/- & $-/+/-$ & + & - & + & + & SS & + \\
\hline W1023-5 & + & - & $\mathrm{KA} /-/-$ & $-/+/-$ & + & - & + & + & SS & + \\
\hline W1087-1 & + & - & $\mathrm{KA} /-/-$ & $-/+/-$ & + & - & + & - & SS & + \\
\hline \multicolumn{11}{|l|}{ Sardinia } \\
\hline W770/11-3 & + & - & KA/-/- & $-/+/+$ & + & + & + & + & SS & + \\
\hline W770/11-4 & + & - & $\mathrm{KA} /-/-$ & $-1+1+$ & + & - & + & + & SS & + \\
\hline W780/11-4 & + & - & $\mathrm{KA} /-/-$ & $-1+/-$ & + & - & + & + & SS & + \\
\hline VC780-6 & - & + & $\mathrm{KA} /-/-$ & $-/+/+$ & + & - & + & + & SS & + \\
\hline
\end{tabular}

CPC, cellobiose-polymyxin b-colistin; TCBS, thiosulfate-citrate-bile salts-sucrose; KIA, Kligler Iron Agar; ONPG, ortho-nitrophenyl- $\beta$-galactoside; W, Vibrio vulnificus; KA, Kligler Agar; S, sensitive; R, resistant; NG, no growth; VC, Vibrio cholerae. 
ylenediaminetetraacetic acid (TAE) buffer (Sigma Aldrich, St. Louis, MO, USA); Gel Red Nucleic Acid Stain (Biotium, Hayward, CA, USA) was utilized as fluorescent nucleic acid stain, and bromophenol blue with $30 \%$ glycerol in PCR water and TrackIt ${ }^{\mathrm{TM}} 100$ bp DNA Ladder (Invitrogen) as loading buffer. The PCR products were evidenced by the transilluminator Bio-Rad Gel Doc ${ }^{\mathrm{TM}}$ XR, Trans-UV at $302 \mathrm{~nm}$.

Samples from SR were also analyzed utilizing a multiplex PCR protocol developed in our laboratory for the simultaneous detection of $V$. parahaemolyticus, $V$. cholerae, and $V$. vulnificus directly on homogenate samples, targeting the species-specific genes for $V$. cholerae (toxRC), V. parahaemolyticus (toxRP) and $V$. vulnificus (vvhA). Briefly, $25 \mathrm{~g}$ of shellfish homogenate was enriched overnight in $225 \mathrm{~mL}$ of Alkaline Peptone Water (Oxoid), then $1 \mathrm{~mL}$ was centrifuged at $19.000 \mathrm{x}$ g at $4^{\circ} \mathrm{C}$ for $5 \mathrm{~min}$. After the removal of supernatant, the pellet was washed with $1 \mathrm{~mL}$ of sterile $\mathrm{H}_{2} \mathrm{O}$, and the PCR reaction was performed following the same steps already described for the simplex PCR. To compare data obtained from shellfish of the two investigated areas, statistical analy- ses were performed by the unpaired t-test for Vibrio spp. abundance, and the chi-square test for the percentage of detection of $V$. parahaemolyticus, V. cholerae, and V. vulnificus, utilizing the Prism version 6.0 software (GraphPad Software Inc, San Diego, CA, USA). A confidence interval at the $95 \%$ level $(\mathrm{P}<0.05)$ was considered significant.

\section{Results}

In order to be concise, single data on Vibrio spp. abundance are omitted. The mean value of Vibrio spp., expressed as colony-forming units $\left(\mathrm{CFU} \mathrm{g} \mathrm{g}^{-1}\right)$ resulted $4.74 \log _{10}(\mathrm{SD}=0.66)$ in shellfish from ER and $5.34 \log _{10}(\mathrm{SD}=1.36)$ in shellfish from SR, pointing at a significant difference between the two areas $(\mathrm{P}<0.05)$.

Results on the isolation and characterization of $V$. parahaemolyticus, V. cholerae, and $V$. vulnificus are reported taking into consideration more than one strain for samples only when isolates showed different genotype or phenotype. The biochemical characteristics of isolates confirmed as $V$. parahaemolyticus, 24 from ER samples and 10 from SR samples, are reported in Table 1.

Two samples from ER harbored simultaneously different strains (VP734 strains 5 and 12; VP1048 strains 1 and 6), and a discrete number of strains showed unusual characteristics, being sucrose positive on TCBS (5.9\%), producing gas or $\mathrm{H}_{2} \mathrm{~S}$ on Kligler Iron Agar (KIA) (14.7\%), ornithine negative (32.4\%), sensitive to $0 / 12910 \mu \mathrm{g}$ (50\%), ortho-nitrophenyl- $\beta$ galactoside (ONPG) positive $(8.8 \%)$, citrate negative (26.1\%), gelatinase negative (26.1\%). The biochemical characteristics of isolates confirmed as $V$. vulnificus, 20 from ER and 3 from SR, are reported in Table 2.

Different strains were simultaneously present in 3 samples from ER (VV731 strains 16, 17, 18; VV734 strains 4, 6, 8; VV776 strains 6, 8, $10)$ and 1 samples from SR (VV770/11 strains 3 and 4), and a discrete number of strains showed unusual characteristics, being sucrose positive on TCBS (26.1\%), no growth on $\mathrm{m}$ CPC agar (4.3\%) producing gas and $\mathrm{H}_{2} \mathrm{~S}$ on KIA (4.3\%), ornithine negative (56.5\%), lysine negative $(4.3 \%)$, citrate positive $(26.1 \%)$

Table 3. Polymerase chain reaction-based genotyping of Vibrio vulnificus and Vibrio cholerae strains isolated in the present study.

\begin{tabular}{|c|c|c|c|c|c|c|c|c|}
\hline Strain & vvhA & hsp & $v c g C$ & 16S B & CPS1 & $v c g E$ & $16 \mathrm{SA}$ & CPS2 \\
\hline \multicolumn{9}{|c|}{ Emilia Romagna } \\
\hline W628-7 & + & + & - & - & + & + & + & - \\
\hline W731-16 & + & + & - & - & - & + & + & + \\
\hline W731-17 & + & + & - & - & - & + & + & + \\
\hline W731-18 & + & + & - & - & - & + & + & + \\
\hline W734-4 & + & + & + & + & + & - & - & - \\
\hline W734-6 & + & + & - & - & - & + & + & + \\
\hline W734-8 & + & + & - & - & + & + & + & - \\
\hline W734-13 & + & + & - & - & - & + & + & + \\
\hline W734-15 & + & + & - & - & - & + & + & + \\
\hline W734-16 & + & + & + & + & + & - & - & - \\
\hline W734-17 & + & + & + & + & + & - & - & - \\
\hline W734-18 & + & + & - & - & - & + & + & + \\
\hline W759-14 & + & + & - & - & - & + & + & + \\
\hline W776-6 & + & + & - & - & - & + & + & + \\
\hline W776-8 & + & + & - & - & - & + & + & + \\
\hline W776-10 & + & + & - & - & - & + & + & - \\
\hline W786-10 & + & + & + & + & + & - & - & - \\
\hline W1023-4 & + & + & - & - & + & + & + & - \\
\hline W1023-5 & + & + & + & - & + & + & + & + \\
\hline W1087-1 & + & + & - & - & + & + & + & + \\
\hline \multicolumn{9}{|l|}{ Sardinia } \\
\hline W770/11-3 & + & + & - & - & - & + & + & + \\
\hline W770/11-4 & + & + & - & - & - & + & + & + \\
\hline \multirow[t]{2}{*}{ W780/11-4 } & + & + & - & - & - & + & + & - \\
\hline & toxRC & hlyA & tcpI & tcpA & $\operatorname{ctxA}$ & $\operatorname{ctx} B$ & stn sto & \\
\hline VC780-6 & + & + & - & - & - & - & - & \\
\hline
\end{tabular}

W, Vibrio vulnificus; VC, Vibrio cholerae. 
gelatinase negative (26.1\%). The only one strain confirmed as $V$. cholerae (Table 2) showed the typical phenotypic traits of the specie, being sucrose positive on TCBS, gas and $\mathrm{H}_{2} \mathrm{~S}$ not produced on KIA, arginine negative, lysine and ornithine positive, sensitive to 0/129 $10 \mu \mathrm{g}$, ONPG positive, citrate negative.

The genotyping of $V$. parahaemolyticus was performed for 3 gene markers, and considering redundant the presentation of a table, data are omitted. All strains showed positivity to the specie-specific gene marker toxRP. Among the isolates from ER shellfish, 27.3\% were positive for the pathogenic gene markers, of which $18.2 \%$ trh positive (VP731/11, VP734/12, VP1048/1, VP1087/6), and 9.1\% tdh positive (VP734-5 e VP1048-6), with samples VP734 and VP1048 harboring simultaneously different strains. None of the isolates from SR shellfish showed positivity to the pathogenic gene markers. The genotyping of the $V$. vulnificus isolates, performed by several gene markers, justifies a complete presentation, and data are reported in Table 3. All isolates were positive to the specie-specific gene markers $v v h a$ and $h s p$ and those from ER shellfish evidenced 37.5\% positivity for the $v c g \mathrm{C}$ gene.

The complete environmental pattern $(v c g \mathrm{E}$, $16 \mathrm{~S} \mathrm{~A}, \mathrm{CPS} 2$ ) was found in $56.5 \%$ of the strains, and the complete clinical pattern ( $v c g \mathrm{C}, 16 \mathrm{~S} \mathrm{~B}, \mathrm{CPS} 1)$ in $17.4 \%$ of the strains, all from ER samples. The remaining strains showed a mixed pattern being $v c g \mathrm{E}, 16 \mathrm{~S} \mathrm{~A}$, CPS1 (17.4\%) or untypeable for CPS marker, being neither CPS1 nor CPS2 positive (8.7\%). As a result of phenotyping and genotyping of isolates, shellfish batches from ER resulted positive for $V$. parahaemolyticus (27.8\%) and $V$. vulnificus $(10.1 \%)$, but negative for $V$. choler$a e$. Shellfish batches from SR resulted positive for V. parahaemolyticus (30.3\%), V. vulnificus (6.1\%) and $V$. cholerae (3\%). The only one strain of $V$. cholerae isolated from SR shellfish was negative to all the pathogenic gene markers utilized in the study (Table 3). No significant differences emerged between the two areas $(\mathrm{P}>0.05)$.

The application of our Multiplex PCR protocol, performed on SR samples, confirmed the results obtained by the cultural method for $V$. vulnificus, while evidenced more than twofold the positivity for $V$. parahaemolyticus (63.6 vs $30.3 \%)$. These data suggest that $V$. parahaemolyticus population in shellfish may comprise a consistent amount of dead and/or viable but not culturable strains. The failure to evidence $V$. cholerae was unexpected, and requires further investigations.

\section{Discussion}

Members of the genus Vibrio are ubiquitous heterotrophic bacteria of the marine environments, and are normally accumulated in shellfish, representing a feed source together with plankton and other organisms. The present study focused on Vibrio spp. abundance and the prevalence of the potentially pathogenic members of the genus $V$. parahaemolyticus, $V$. vulnificus and $V$. cholerae in $R$. philippinarum from two Italian regions, ER and SR. Notwithstanding the high ecological diversity between ER and SR marine production areas, only the difference on the abundance of Vibrio spp., being $4.74 \log _{10}$ and $5.34 \log _{10}$ respectively, resulted statistically significant $(\mathrm{P}<0.05)$, whereas the prevalence of samples positive for the target species, was not statistically significant $(\mathrm{P}>0.05)$. This fact suggests that the presence of the potentially pathogenic subpopulations of environmental vibrios is unrelated to the total vibrio population, as reported elsewhere (Johnson et al., 2012).

The utilization of TCBS agar $\mathrm{NaCl} 3 \%$ with incubation at $20^{\circ} \mathrm{C}$, allowed to the recovery of Vibrio spp. in all samples, with an abundance indubitably higher than previously reported in environmental samples from the Adriatic Sea, where TCBS agar without $\mathrm{NaCl}$ added and/or incubation at $37^{\circ} \mathrm{C}$, were employed (Barbieri et al., 1999; Ripabelli et al., 1999; Rubini et al., 2009).

The triple plating methods proposed by Williams et al. (2013) for V. vulnificus, allowed to the recovery of sucrose positive variants of $V$. parahaemolyticus and $V$. vulnificus, and $V$. vulnificus variants unable to grow on $\mathrm{m}$-CPC agar, confirming that CAV easily differentiates $V$. parahaemolyticus from $V$. vulnificus, $V$. cholerae and other vibrios with great sensitivity, as reported elsewhere (Di Pinto et al., 2011).

The prevalence of $V$. parahaemolyticus in ER shellfish resulted $27.8 \%$, in agreement with another study on shellfish from Veneto region, facing the North Adriatic Sea as well, showing a positivity of $27.5 \%$. In the same study, the prevalence of $V$. parahaemolyticus in shellfish from Sardinia resulted 56.7\% (Suffredini et al., 2014), significantly higher with respect to our study, where the positivity of SR shellfish resulted $30.3 \%$.

Potentially pathogenic $V$. parahaemolyticus strains were recovered only from ER shellfish with a percentage of $27.3 \%$, and similar values (33.3\%) have been reported for strains isolated from mussels of the Ionian Sea, even if targeting only the $t d h$ gene (Di Pinto et al., 2008), whereas our strains resulted $18 \%$ trh + and $9.1 \% t d h+$.

$V$. cholerae was recovered in 3\% of SR shellfish sample and was absent in ER shellfish samples. These low values of prevalence are in agreement with data previously reported for Italian mussels (Ottaviani et al., 2009). V. vulnificus was found in $10.1 \%$ of ER shellfish and
$6.1 \%$ of SR shellfish, but scant information are available for a comparison.

The phenotypic and genetic traits of $\mathrm{V}$. vulnificus strains isolated in the present study were highly variable, as previously reviewed (Jones and Oliver, 2009), whereas the variability of $V$. parahaemolyticus resulted higher than commonly accepted, but confirming some recent findings (Rojas et al., 2011).

\section{Conclusions}

The popularity of shellfish in the diet is growing, however, concerns have been raised worldwide regarding health risks from shellfish contaminated with human pathogens of anthropogenic origin, particularly the enteroviruses, and the autochthonous bacteria $V$. parahaemolyticus, $V$. cholerae, and $V$. vulnificus. Moreover, it is useful to outline that the depuration treatment, utilized worldwide to purge shellfish from faecal contaminants in clean seawater, is largely considered unsatisfactory with respect to enteroviruses and vibrios (Serratore et al., 2014). In order to develop measures for human health protection based on a robust risk analysis, the acquisition of data on the prevalence of $V$. parahaemolyticus, $V$. cholerae, and $V$. vulnificus, and their potential pathogenicity traits, is fundamental. On the other hand, the relatively low prevalence of potentially pathogenic strains emerged in the present study, even if not negligible, outline the necessity to couple cultural methods with the genotyping approach, to properly identify safe versus unsafe shellfish, avoiding unjustified economical losses consequent to the rejection of product evaluated only on the basis of the cultural methods, that may give false positive results and are unable to ascertain the potential pathogenicity of isolates. Giving the scant information of concern actually available for the Italian production areas, further researches are needed, but above all, the competent authorities should become aware of the necessity to implement a systematic microbiological control of shellfish production areas, today routinely limited to the faecal contaminants, including an appropriate survey of V. parahaemolyticus, V. cholerae, and V. vulnificus.

\section{References}

Barbieri E, Falzano L, Fiorentini C, Pianetti A, Baffone W, Fabbri A, Matarrese P, Casiere A, Katouli M, Kühn I, Möllby R, Bruscolini F, Donelli G, 1999. Occurrence, diversity, and pathogenicity of halophilic Vibrio spp. and non-01 Vibrio cholerae from estuarine waters along the Italian Adriatic coast. 
Appl Environ Microbiol 65:2748-53.

Ceccarelli D, Hasan NA, Huq A, Colwell RR, 2013. Distribution and dynamics of epidemic and pandemic Vibrio parahaemolyticus virulence factors. Front Cell Infect Microbiol 3:1-9.

Di Pinto A, Ciccarese G, De Corato R, Novello L, Terio V, 2008. Detection of pathogenic Vibrio parahaemolyticus in southern Italian shellfish. Food Control 19:1037-41.

Di Pinto A, Terio V, Novello L, Tantillo G, 2011. Comparison between thiosulphate-citratebile salt sucrose (TCBS) agar and CHROMagar Vibrio for isolating Vibrio parahaemolyticus. Food Control 22:124-7.

European Commission, 2001. Opinion of the Scientific Committee on veterinary measures relating to public health on Vibrio vulnificus and Vibrio parahaemolyticus. European Commission, Bruxelles, Belgium.

FA0, 2014. The state of world fisheries and aquaculture. Status and trend. Food and Agriculture Organization of the United Nations, Rome, Italy.

Fykse EM, Skogan G, Davies W, Olsen JS, Blatny JM, 2007. Detection of Vibrio cholerae by real-time nucleic acid sequence-based amplification. Appl Environ Microbiol 73:1457-66.

Guglielmetti P, Bravo L, Zanchi A, Montè R, Lombardi G, Rossolini GM, 1994. Detection of the Vibrio cholerae heat stable enterotoxin gene by polymerase chain reaction. Mol Cell Probes 8:39-44.

Han F, Wang F, Ge B, 2011. Detecting potentially virulent Vibrio vulnificus strains in raw oysters by quantitative loop-mediated isothermal amplification. Appl Environ Microbiol 77:2589-95.

Johnson CN, Bowers JC, Griffitt KJ, Molina V, Clostio RW, Pei S, Laws E, Paranjpye RN, Strom MS, Chen A, Hasan NA, Huq A, Noriea NF 3rd, Grimes DJ, Colwell RR, 2012. Ecology of Vibrio parahaemolyticus and Vibrio vulnificus in the coastal and estuarine waters of Louisiana, Maryland, Mississippi, and Washington (United States). Appl Environ Microbiol 78:724957.

Jones MK, Oliver JD, 2009. Vibrio vulnificus: disease and pathogenesis. Infect Immun 77:1723-33.

Kaysner CA, DePaola A, 2004. Vibrio. Available from: http://www.fda.gov/Food/ Food ScienceResearch/LaboratoryMethods/ucm 070830.htm

Noguerola I, Blanch AR, 2008. Identification of Vibrio spp. with a set of dichotomous keys. J Appl Microbiol 105:175-85.

Ottaviani D, Leoni F, Rocchegiani E, Santarelli S, Canonico C, Masini L, DiTrani V, 2008. First clinical report of pandemic Vibrio parahaemolyticus 03:K6 infection in Italy. J Clin Microbiol 46:2144-5.

Ottaviani D, Leoni F, Rocchegiani E, Santarelli S, Masini L, Di Trani V, Canonico C, Pianetti A, Tega L, Carraturo A, 2009. Prevalence and virulence properties of non-01 non-0139 Vibrio cholerae strains from seafood and clinical samples collected in Italy. Int J Food Microbiol 132:47-53.

Pazzani C, Scrascia M, Dionisi AM, Maimone F, Luzzi I, 2006. Molecular epidemiology and origin of cholera reemergence in Italy and Albania in the 1990s. Res Microbiol 157:508-12.

Ripabelli G, Sammarco ML, Grasso GM, Fanelli I, Caprioli A, Luzzi I, 1999. Occurrence of Vibrio and other pathogenic bacteria in Mytilus galloprovincialis (mussels) harvested from Adriatic Sea, Italy. Int J Food Microbiol 49:43-8.

Rivera ING, Chun J, Huq A, Sack RB, Colwell RR, 2001. Genotypes associated with virulence in environmental isolates of Vibrio cholerae. Appl Environ Microbiol 67:2421-9.

Rojas MVR, Matté MH, Dropa M, Da Silva ML, Matté GR, 2011. Characterization of Vibrio parahaemolyticus isolated from oysters and mussels in São Paulo, Brazil. Rev I Med Trop 53:201-5.

Rubini S, Losio MN, Pavoni E, Bianchi L, Galletti G, Scordella G, Bresolin R, Pongolini S, Piano A, Serratore P, 2009. Occurrence of Vibrio spp. in shellfish harvested from Emilia Romagna coast (Northwestern Adriatic Sea, Italy). In: Lassus P, ed. Proceedings of the 7th International Conference on Molluscan Shellfish Safety, 2009 June 14-19, Nantes, France. Ifremer, Issy-les-Moulineaux, France, p. 193.

Sanjuán E, González-Candelas F, Amaro C, 2011. Polyphyletic origin of Vibrio vulnificus biotype 2 as revealed by sequencebased analysis. Appl Environ Microbiol 77:2688-95.

Schmidt VT, Reveillaud J, Zettler E, Mincer TJ, Murphy L, Amaral-Zettler LA, 2014. Oligotyping reveals community level habitat selection within the genus Vibrio. Front Microbiol 5:563.
Serratore P, Ciulli S, Piano A, Cariani A, 2014. Criticism of the purification process of bivalve shellfish. Literature review and our industrial research experiences. In: Hay RM, ed. Shellfish, human consumption health implication and conservation concerns. Nova publishers, New York, NY, pp. 1-50.

Serratore P, Piano A, Piraccini S, Trentini M, Zavatta E, Grodzki M, Valeri ML, 2009. Survey of V. cholerae, V. vulnificus and V. parahaemolyticus, in bivalve molluscs of the Adriatic sea and proposal of an analytical protocol. Ital J Food Sci 1:33-8.

Serratore P, Turtura GC, Rinaldini E, Milandri S, Presepi D, 1999. Phenotypic characterization of some bacterial populations belonging to the genus Vibrio. Ann Microbiol Enzim 49:79-88.

Suffredini E, Mioni R, Mazzette R, Bordin P, Serratore P, Fois F, Piano A, Cozzi L, Croci L, 2014. Detection and quantification of Vibrio parahaemolyticus in shellfish from Italian production areas. Int $\mathrm{J}$ Food Microbiol 184:14-20.

Tall A, Teillon A, Boisset C, Delesmont R, Touron-Bodilis A, Hervio-Heath D, 2012. Real-time PCR optimization to identify environmental Vibrio spp. strains. J Appl Microbiol 113:361-72.

Thandavarayan R, Goutam C, Gururaja PP, Sumio S, 2014. Vibrio fluvialis: an emerging human pathogen. Front Microbiol 5:1-8.

Turolla E, 2008. La venericoltura in Italia. In: Lovatelli A, Farías A, Uriarte I, eds. Estado actual del cultivo y manejo de moluscos bivalvos y su proyección futura: factores que afectan su sustentabilidad en América Latina. Proceedings of the FAO Regional Laboratory, 20-24 August 2007, Puerto Montt, Chile. FAO, Rome, Italy, pp. 177-88.

Ward L, Bej A, 2006. Detection of Vibrio parahaemolyticus in shellfish by use of multiplexed Real-time PCR with TaqMan fluorescent probes. Appl Environ Microbiol 72:2031-42.

Williams TC, Froelich B, Oliver JD, 2013. A new culture-based method for the improved identification of Vibrio vulnificus from environmental samples, reducing the need for molecular confirmation. J Microbiol Meth 93:277-83.

Zhang XH, Austin B, 2005. Haemolysins in Vibrio species. J Appl Microbiol 98:1011-8. 